\title{
Acerca de una posible consulta democrática para la independencia de cataluña [u otras regiones de España]. Una revisión desde la Teoría de Elección Social
}

\author{
Ricardo Alvira
}

\section{Introducción: tres principios fundamentales de la elección social}

Desde hace algún tiempo, y con mayor notoriedad a partir de las elecciones de Diciembre de 2016, se ha vuelto frecuente escuchar de algunos partidos políticos españoles la expresión "derecho a decidir", en alusión a su voluntad de que los habitantes de ciertos territorios puedan decidir, autónomamente de los habitantes de otros territorios de España, si prefieren seguir formando parte de España o constituirse en Estados independientes.

Los portavoces/integrantes de estos partidos políticos argumentan que dicho derecho a decidir autónomamente del resto de españoles es un derecho básico de la democracia.

Pero... ¿Es esto verdad? ¿Es el derecho de los ciudadanos de un territorio dentro del Estado español a decidir independientemente del resto de ciudadanos españoles su continuidad o no dentro de dicho Estado, un derecho inherente a la democracia?

Vamos a demostrar que no lo es; lo que haremos revisando que el "derecho a decidir" en los términos que plantean estos grupos políticos, implica renunciar a tres cuestiones que los expertos en Teoría de Elección Social coinciden que debe satisfacer una decisión colectiva para ser democrática:

La anonimidad [May, 1952], que alude a la igualdad entre todos los individuos, y requiere que se otorgue el mismo valor al voto de todos ellos. Es decir, que no se prioricen los derechos de unos individuos sobre los de otros. La única excepción aceptada es otorgar más valor al voto de alguna persona en caso de empate entre opciones.

- La neutralidad [May, 1952], que exige tratar igual a todas las opciones, y requiere que el planteamiento de la decisión no favorezca una opción frente a las demás, es decir, que no haga más probable que una opción resulte elegida frente a otras. Solamente se acepta romper esta premisa en dos situaciones:

- cuando se produce un empate entre continuar la tendencia actual/mantener el statu quo y otra alternativa; habitualmente se prefiere continuar la tendencia actual/mantener el statu quo ${ }^{2}$.

\footnotetext{
1 Este artículo se terminó de escribir en julio de 2017, por tanto, con anterioridad a la consulta que, en una situación de enfrentamiento con el Gobierno Central, las autoridades catalanas celebraron el 1 de octubre de 2017. Es por esta razón que solo incluimos algunos comentarios acerca de dicha consulta en notas al pie.

2 En el marco de la Teoría de Elección Social, un empate entre dos opciones implica indiferencia colectiva entre ambas. En dicha situación, se considera preferible mantener el curso actual. A igual utilidad colectiva, el cambio implica menor eficiencia [esfuerzo en relación al resultado obtenido] y menor utilidad esperada [la utilidad esperada es resultado de multiplicar la utilidad colectiva por la probabilidad de éxito], puesto que el cambio implica mayor esfuerzo/riesgo.
} 
- cuando el tema a decidir puede tener gran impacto para la sociedad e implica elevada incertidumbre, se suele exigir que la opción que promueve el cambio sea apoyada por una "mayoría cualificada" [e.g., $3 / 5$ o $2 / 3$ ] de ciudadanos ${ }^{3}$.

La no restricción de las opciones elegibles [Arrow, 1951], que exige que quien organiza la elección no limite -para favorecer sus propios intereses- las opciones acerca de las cuales los individuos pueden expresar su preferencia. Solamente se admite excluir de las opciones elegibles, aquellas que no son medioambiental, social, económica o tecnológicamente posibles.

Las condiciones anteriores son consideradas en el campo de la Elección social tres premisas esenciales para considerar democrática una decisión colectiva porque a su vez aluden a dos cuestiones sustanciales:

El Artículo 01 de la Declaración de Derechos Fundamentales [incorporado de una forma u otra en la mayoría de Constituciones], que establece que todas las personas son iguales ante la ley [tienen iguales derechos], y que participar en las decisiones públicas es un derecho que debe ejercerse en igualdad de condiciones ${ }^{4}$.

a la voluntad de impedir la manipulación de las elecciones colectivas. Satisfacer estas tres premisas nos permite considerar que quien organiza una elección colectiva no trata de manipularla para obtener su resultado preferido; i.e., no la diseña para hacer más probable que su opción favorita resulte elegida, independientemente de las preferencias reales de los ciudadanos [i.e., que resulte elegida no democráticamente].
Por tanto, saber si la petición del "derecho a decidir autónomamente" satisfaría las tres cuestiones anteriores no es una cuestión baladí. Si el denominado derecho a decidir no satisface las condiciones anteriores, llevaría a una decisión que podría no ser democrática, y la legitimidad de dicho derecho [y de las decisiones resultantes de aplicarlo] no podría ser sustentada sobre el concepto de democracia.

Vamos a revisar si las cumple o no, y para mayor claridad las referimos a la región cuya "independencia o no" está generando mayor debate en la actualidad en España: Cataluña ${ }^{5}$.

\section{2. ¿Cumple el "derecho a decidir" la condición de "anonimidad"?}

La Anonimidad exige que para tomar la decisión colectiva se otorgue el mismo valor a las preferencias de todos los individuos. Alude a la igualdad en los derechos de todas las personas. Vamos a revisar si el planteamiento de los partidos independentistas satisface esta condición.

La Constitución Española [CE] afirma en el Título Preliminar, Art. 2 que:

Art. 2. Unidad de la Nación y derecho a la autonomía. La Constitución se fundamenta en la indisoluble unidad de la Nación española, patria común e indivisible de todos los españoles, y reconoce y garantiza el derecho a la autonomía de las nacionalidades y regiones que la integran y la solidaridad entre todas ellas ${ }^{7}$.

Por tanto, cualquier modificación de la delimitación geográfica de España implica una modificación de dicho artículo, cuyo proceso debe hacerse siguiendo lo estipulado en el Art. 168, que establece que:

Art 168. Reformas esenciales de la Constitución

\footnotetext{
3 El principio es el mismo que el explicado en la nota anterior. Cuanto mayor es la incertidumbre, mayor tiene que ser la diferencia de utilidad colectiva [i.e., la diferencia entre personas a favor del cambio y a favor de la permanencia], para que la utilidad esperada del cambio supere a la de mantener el statu quo. Adicionalmente, en Estados Federales [e.g., Suiza] suelen imponerse requerimientos de doble mayoría; más de la mitad de ciudadanos en más de la mitad de estados [cantones] debe manifestarse a favor.

4 * En realidad, participar en las decisiones colectivas es un derecho y un deber que debe ser ejercido/soportado por todos los ciudadanos en igualdad de condiciones: Como derecho, es la posibilidad de cada individuo de condicionar las decisiones colectivas de acuerdo a sus valores/preferencias, valorados/as en las mismas condiciones que los/as de los demás ciudadanos.

* Como deber, es la obligación que asume cada individuo de aceptar la decisión resultante, incluso si es la opuesta a su decisión preferida. En cierto modo, en las decisiones colectivas votadas cualquier individuo participa en la decisión [vote o no vote] puesto que asume el compromiso de aceptar el resultado de la misma.

5 Para revisar el enfoque de los partidarios de la independencia, utilizamos el texto redactado por Constituïm [que designamos Cï], que a día de hoy parece ser el referente de lo que sería la Constitución de Cataluña, en el caso de producirse la independencia. Sin embargo, dada su no oficialidad, no limitamos el análisis a la revisión de este texto.

6 Además del Art.01 de la Declaración Fundamental [AGNU, 1948], este requerimiento de la igualdad de valor al voto de todos los individuos está implícito en el Art 09 de la Constitución Española [CGE, 1978] y el Art 2.1. Voting Rights [CEDD; 2009]

7 En el momento actual en el cual se debate si España es un "país de países", conviene recalcar el diferente significado del término 'nación' cuando se escribe con mayúscula [equivale a 'Estado'] y cuando se escribe con minúscula [equivalente a 'pueblo'/cultura]
} 
1. Cuando se propusiere la revisión total de la Constitución o una parcial que afecte al Título preliminar, al Capítulo II, Sección $1 .^{\mathrm{a}}$, del Título I, o al Título II, se procederá a la aprobación del principio por mayoría de dos tercios de cada Cámara, y a la disolución inmediata de las Cortes.

2. Las Cámaras elegidas deberán ratificar la decisión y proceder al estudio del nuevo texto constitucional, que deberá ser aprobado por mayoría de dos tercios de ambas Cámaras.

3. Aprobada la reforma por las Cortes Generales, será sometida a referéndum para su ratificación.

Esto implica que un proceso de independencia de Cataluña de España requiere su aprobación por más de dos tercios de los representantes de ambas Cámaras [en las cuales hay representantes catalanes], la convocatoria de elecciones generales [en las cuales votarían ciudadanos catalanes], una segunda aprobación por más de 2/3 de los representantes de las nuevas Cámaras [en las cuales habría representantes catalanes] y, posteriormente, la votación a favor de más del $50 \%$ de los ciudadanos españoles [entre los cuales habría ciudadanos catalanes].

Es decir, se trata de un proceso en el cual primero ejercen su derecho a votar los representantes políticos y solo si estos se pronuncian a favor del proceso, lo ejercen los ciudadanos. Y es importante destacar que, en ambos casos, políticos y ciudadanos catalanes poseen el "derecho a decidir" en igualdad de condiciones que el resto de políticos y ciudadanos españoles.

Esto es importante porque nos permite entender que representantes y ciudadanos catalanes no pueden adquirir un derecho que ya poseen. Por tanto, los partidos proindependencia no están en realidad pidiendo adquirir el "derecho a decidir", sino la eliminación del derecho actual del resto de políticos/ciudadanos españoles a que su preferencia sea valorada en dicha decisión ${ }^{8}$.

Implica otorgar diferentes derechos a políticos/ciudadanos con base en una circunstancia personal [residir o no en Cataluña], y atenta directamente contra el Principio de Anonimidad entre ciudadanos españoles: unos pueden participar en la decisión y otros no.

Para entendernos, un ejemplo equivalente es que los políticos y ciudadanos de Barcelona decidieran organizar dentro de unos días un referéndum para votar su independencia del resto de Cataluña, y contabilizar solo el voto de los políticos y habitantes de Barcelona, alegando que Barcelona posee una identidad independiente del resto de Cataluña [lo cual es incuestionable] y que, por tanto, el voto del resto de políticos/ciudadanos catalanes no necesita ser tenido en cuenta para dicha consulta [argumento que sería bastante cuestionable].

Otro ejemplo sería que lo decidieran los ciudadanos del Val d"Aran, quienes, incluso, podrían alegar que poseer una lengua propia diferente del catalán -el aranés- demuestra su identidad propia [lo cual es otra vez incuestionable] y naturaleza independiente del resto de Cataluña [lo que vuelve a ser cuestionable] $]^{9}$.

De hecho, en los términos descritos por los partidos independentistas, el "derecho a decidir" implicaría que cualquier circunscripción administrativa [es decir, cualquier ámbito con capacidad de tomar decisiones colectivas propias] en la que el "sí" fuera preferido al "no", debería tener el derecho a independizarse, pero cualquier circunscripción en la que el "no" fuera preferido al "sí" debería tener el derecho a seguir formando parte del Estado español.

Es decir, si no se establecen ámbitos a los cuales se asigne el derecho a decidir independientemente, cualquier entorno geográfico podría segregarse del resto. No solo Cataluña podría segregarse de España; Barcelona podría decidir convertirse en ciudad autónoma; Lérida podría decidir integrarse en Francia; el Valle de Arán podría decidir unirse al resto de regiones pirenaicas y constituirse en reino independiente...

Si revisamos los resultados obtenidos en las elecciones autonómicas de Cataluña, el derecho a decidir en los términos anteriores implicaría la desintegración de Cataluña, porque

8 Hemos indicado anteriormente que el derecho de un ciudadano a votar en una decisión implica un derecho [que su preferencia sea valorada], pero también un deber [el de respetar la decisión resultante incluso si no le gusta]. En este sentido, el planteamiento de los partidos pro-independencia es quitar a la mayoría de ciudadanos españoles el derecho a votar [i.e., a que su preferencia sea valorada], pero manteniendo su obligación de respetar la decisión resultante. Propugna una ruptura del paradigma democrático de que la aceptación del resultado de una votación es una consecuencia lógica del derecho de que la preferencia sea valorada en la misma.

9 Algunos políticos pro-independencia argumentan que el Arán tiene ya el derecho a la autodeterminación otorgado por la Generalitat de Cataluña mediante la Ley $1 / 2015$, de 5 de febrero, del régimen especial de Arán, que en su Disposición Adicional Primera afirma que "El Parlamento de Cataluña reconoce el derecho del pueblo aranés a decidir su futuro" [es importante indicar que en el momento de aprobarse esta ley, el parlamento de Cataluña tenía mayoría de políticos pro-independencia]. El hecho de que no se explique ni el contenido de ese "derecho a decidir" ni la forma en que puede ser ejercido, otorga un escaso valor legal a esta Disposición Adicional. En cualquier caso, en la pasada 'consulta' del 1 de octubre no se ofreció la opción de que el Arán decidiese su futuro independientemente del resto de Cataluña, obligando al Arán a seguir el curso que decidiese el conjunto de catalanes. 
aproximadamente en la mitad de las circunscripciones ganaron partidos políticos pro-independencia, mientras que en la mitad de las circunscripciones ganaron partidos políticos que apoyan la continuación en el marco del Estado español $_{10}$.

Dado que los partidos pro-independencia no parecen ser favorables a la desintegración de Cataluña, se antoja evidente que su requerimiento del "derecho a decidir" solo se refiere en realidad al "derecho a decidir si el conjunto de Cataluña se independiza o no”, pero no al "derecho a decidir" en relación con otras opciones posibles.

Es decir, estos partidos no estarían pidiendo que los ciudadanos catalanes adquieran el "derecho a decidir autónomamente acerca de cualquier cuestión”, sino que adquieran el derecho a decidir acerca de una única cuestión planteada precisamente por los miembros de estos partidos, cuyas preferencias adquieren así más valor que las del resto de ciudadanos catalanes, rompiéndose así también el principio de anonimidad entre ciudadanos catalanes ${ }^{11}$.

Complementariamente, esto implica ausencia de neutralidad en el tratamiento de las opciones posibles, favoreciendo una de las posibles decisiones implícitas en el "derecho a decidir" frente a todas las demás. ¿Por qué Cataluña puede constituirse en República Independiente pero no puede hacerlo la Ciudad de Barcelona, la provincia de Lérida o el Val d"Arán? ${ }^{12}$

Una consulta así no sería neutral, y ello nos obliga a revisar lo que implica la "neutralidad" en las elecciones colectivas.

\section{3. ¿Cumple el "derecho a decidir" la condición de "neutralidad"?}

La Neutralidad alude a que una decisión solo es democrática si el procedimiento no favorece a ninguna opción frente a las demás, es decir, si no incrementa la probabilidad de que una opción sea elegida independientemente de las preferencias de los ciudadanos.

Ya hemos visto que el planteamiento de los partidos pro-independencia se aparta de la Neutralidad, favoreciendo una de las preguntas posibles frente a otras preguntas posibles.

Pero también lo hace al plantear un diseño de la consulta que favorece la opción de la independencia frente a la de la permanencia en España. La cuestión clave es que estos partidos políticos no están pidiendo el derecho a "convocar un referéndum", sino el "derecho a decidir autónomamente", que implica el derecho a celebrar tantos referéndums como se quiera.

Supongamos que se acepta dicho derecho. Se celebra un referéndum y la mayoría de ciudadanos convocados vota "no": Cataluña sigue dentro de España.

Evidentemente los partidos proindependencia están descontentos, así que cierto tiempo después exigen otro referéndum. El "derecho a decidir" se lo permite.

Supongamos que se celebra otro referéndum y otra vez la mayoría de ciudadanos vota "no". Como consecuencia, Cataluña continúa siendo parte de España.

Pasa otra vez cierto tiempo y nuevamente estos partidos exigen que se convoque otro referéndum. Esta vez la mayoría de ciudadanos vota "sí". En consecuencia, Cataluña se convierte en una República independiente.

Es evidente que tras su independencia, Cataluña debería redactar y aprobar su propia Constitución. Y aquí surge una pregunta fundamental: ¿preservarían los ciudadanos de la hipotética República Independiente de Cataluña el "derecho a decidir"? ¿Podrían posteriormente en cualquier momento convocar una votación, y si gana el "sí", incorporarse otra vez a España? ${ }^{13}$

La pregunta anterior es fundamental, porque si la respuesta es "no", entonces lo que

10 Hacemos esta afirmación siendo conscientes de que implica cierta simplificación ya que votar a un partido político no implica estar de acuerdo con todo su programa, y además estas elecciones se realizaron utilizando una regla de votación que no satisface la mayoría de criterios aceptados en Elección Social [e.g., incumple el Criterio de Condorcet.

11 Esta ruptura de la igual valoración de las preferencias de los ciudadanos resulta menos evidente ya que no se valoran de diferente manera las preferencias de diferentes ciudadanos expresadas durante la votación -i.e., sus votos-, sino sus preferencias antes de la votación, cuando se decide qué puede, y qué no puede, ser votado. Puede ser más fácil comprenderlo en términos de restricción del universo de opciones elegibles, lo que revisamos más adelante.

12 Es cierto que la Ley $1 / 2015$ consigna un impreciso 'derecho a decidir' del Arán, que en el texto de Constituïm pasa a designarse como un también impreciso 'derecho a la libre determinación' [Título Preliminar. Art 6. Cï]. Sin embargo, esta [poco definida] libre determinación del Arán podría ser eliminada en un futuro por los políticos/ciudadanos catalanes incluso si todos los araneses se opusieran [Art 149 y Art 139 Cï]. En cualquier caso, este 'derecho a la libre determinación' no se consigna con carácter general para cualquier demarcación, i.e.; Cï no considera que el 'derecho a decidir' sea un derecho fundamental de la democracia.

13 Es importante destacar que requerir el derecho a convocar más de un referéndum implica reconocer que las preferencias de los ciudadanos pueden ser diferentes ahora y en el futuro. Implica reconocer que incluso si se produjera un apoyo mayoritario a la independencia en la actualidad, podría ser que en el futuro la misma mayoría de ciudadanos prefiriese volver a la situación actual. Esto requeriría que el 'derecho a decidir' fuera incorporado como derecho fundamental de los ciudadanos, lo que no sucede en el texto de Constituïm. Por el contrario, en dicho texto sí figura en el Título preliminar la naturaleza de Cataluña de 'Estado Independiente'. Como consecuencia, el proceso para realizar un hipotético referéndum de reincorporación de Cataluña a España que establece dicho texto, sería muy complicado y requeriría el voto a favor de $3 / 5$ partes de la Asamblea [Art 147.2 y 148] Sorprendentemente, para convocar el referéndum en la actualidad, la 'Asamblea' catalana solo exige el voto favorable de más del $50 \%$ de los representantes; para votar una hipotética reunificación, exigiría mayor apoyo [más del $60 \%$ ], incumpliendo así la condición de neutralidad. 
los partidos pro-independencia estarían pidiendo tampoco sería el "derecho a decidir autónomamente sobre la independencia de Cataluña o su permanencia en el Estado Español", sino el "derecho a decidir autónomamente sobre la independencia de Cataluña solamente hasta que ésta se produjera", momento en que los catalanes volverían a perder dicho derecho.

Mientras los ciudadanos catalanes voten que quieren continuar en España, las votaciones podrían repetirse indefinidamente, pero si los ciudadanos catalanes votan la independencia, no podrían ya celebrarse más elecciones. Si posteriormente los ciudadanos catalanes se arrepintieran y quisieran votar su reincorporación a España, no podrían hacerlo.

Desde el punto de vista de la neutralidad, constituiría un tratamiento muy diferente de las dos opciones [permanencia/independencia] que los partidos pro-independencia plantean; i.e., un procedimiento inequívocamente diseñado para facilitar la independencia y hacer más difícil la permanencia $^{14}$, independientemente de la voluntad de los ciudadanos catalanes.

Pero incluso si la futura Constitución de una hipotética Cataluña independiente reconociera el derecho de los ciudadanos catalanes a votar periódicamente si preservan su independencia o prefieren reincorporarse a España, la reincorporación futura podría no ser posible incluso si el $100 \%$ de los ciudadanos catalanes se manifestaran a favor de dicha opción ${ }^{15}$.

España habría modificado su Constitución para reflejar la independencia de Cataluña, que ya no sería parte del Estado español. Por tanto la reincorporación de Cataluña a España requeriría modificar otra vez la Constitución Española, y por tanto el voto a favor de más de 2/3 partes de los representantes de las Cámaras legislativas y del 50\% del resto de los ciudadanos españoles.

Si tomamos como referencia el Censo Electoral en 2016 [INE, 2016], y aceptamos el planteamiento de los partidos proindependencia, la independencia de Cataluña se podría conseguir con el voto a favor de más del $50 \%$ de los representantes catalanes y 2.759.927 votos a favor, mientras que la re-unificación posterior con España requeriría el voto a favor de más de 2/3 de los representantes de las Cámaras españolas, el $60 \%$ de los representantes de la Asamblea catalana y 18.259.052 ciudadanos [2.759.927 catalanes y 15.499.125 del resto de España].

Otra vez se hace evidente que el planteamiento del "derecho a decidir independientemente" de estos partidos políticos está pensado para favorecer la independencia frente a la continuidad en España; ambas opciones se tratan de manera muy desigual.

Incluso si los actuales ciudadanos catalanes nunca modificaran su opinión ly por tanto nunca fueran a revisar su decisión de independizarse de España, en caso de tener éxito en ello],... ¿Qué pasaría con los ciudadanos catalanes futuros? ${ }^{16}$. El planteamiento de los partidos pro-independencia incumple la condición de "anonimidad" en el sentido de que promueve la desigualdad intergeneracional de derechos. Los ciudadanos catalanes de ahora podrían decidir autónomamente y en aparente igualdad de condiciones entre la permanencia o la independencia de Cataluña en España; los ciudadanos catalanes del futuro no podrían17.

Tratar igualmente ambas opciones requiere que la opinión del resto de ciudadanos españoles sea considerada en cualquier proceso de búsqueda de independencia, y establecer un criterio de doble mayoría; la modificación de la situación actual solo debería producirse si es aprobada por una mayoría cualificada tanto a nivel de Cataluña como del resto del Estado Español ${ }^{18}$.

Aparentemente, la falta de neutralidad [i.e., parcialidad] del planteamiento del "derecho a decidir" podría solucionarse adoptando otro de los planteamientos que proponen algunos partidos españoles: el derecho a convocar un

14 De hecho, este planteamiento convierte la permanencia en altamente improbable, dada la posibilidad de repetir referéndums indefinidamente que implica el 'derecho a decidir'.

15 Aunque los políticos pro-independencia alegan que este es un escenario casi imposible, en realidad no es así. Por ejemplo, recientes publicaciones científicas sugieren que de no revertirse el proceso de cambio climático, entre un tercio y la mitad de la superficie de Cataluña se hallaría sumergida bajo el mar hacia final de este siglo. Llegados a este punto, es fácil pensar que muchos ciudadanos catalanes quisieran reintegrarse en España para recuperar su derecho actual de vivir en cualquier parte del territorio español, derecho que habrían perdido al producirse la independencia. Complementariamente, es razonable pensar que el resto de españoles, tras un periodo de desconexión de 75 años podrían preferir no aceptar dicha reincorporación de Cataluña, que supondría una mayor competencia por un territorio que se habría convertido en un recurso escaso.

16 Ya hemos hecho anteriormente una referencia al probable elevado impacto del cambio climático sobre Cataluña, que hace altamente probable que muchos ciudadanos catalanes futuros prefieran revertir una posible independencia.

17 En realidad, en el planteamiento de Cï se aprecia una intencionalidad de dificultar al máximo una posible reintegración futura, mediante la rápida eliminación del Castellano, uno de los lazos actuales de Cataluña con el resto de España [la Disposición Transitoria Primera elimina el Castellano como lengua para aquellos nacidos después de 1977].

18 La aparente 'severidad' de esta exigencia se asienta no solo en el requerimiento de Neutralidad, también es un diseño que impide actuaciones en las que una mayoría discrimine a una minoría. Por ejemplo, garantiza que si el $66 \%$ de ciudadanos españoles quisieran expulsar a Cataluña de España, no podrían hacerlo si más del $33 \%$ de los ciudadanos catalanes estuvieran en contra. En opinión de Nicolaus Tideman [comunicación personal, abril 2016], esto no implica la neutralidad, sino la Simetría, pero sugiere que podría ser suficiente para considerar 'adecuado' el planteamiento. 
único referéndum. En este caso, al tratarse de una única consulta, ambas opciones tendrían los mismos requisitos para resultar elegidas y, por tanto, serían tratadas igual.

Pero, otra vez se produciría una desigualdad intergeneracional de derechos. Conceder a los ciudadanos catalanes actuales el derecho a convocar un único referéndum no repetible implica negar dicho derecho a los ciudadanos catalanes futuros; implica desigual tratamiento de personas/votantes.

En otras palabras, los ciudadanos catalanes actuales podrían decidir entre la permanencia o no de Cataluña en España, pero los ciudadanos catalanes futuros [i.e., sus hijos, sus nietos,..] no podrían. La celebración de un único referéndum discrimina entre ciudadanos catalanes actuales y futuros, algo inherentemente no-democrático.

¿Es democrático modificar el marco de derechos ciudadanos para priorizar los derechos de los ciudadanos catalanes actuales sobre los derechos de los ciudadanos catalanes futuros?

La Anonimidad requiere que el "derecho a decidir" no se establezca o se establezca para siempre, pero no acepta que se ejerza solo una vez. O bien se niega la posibilidad de celebrar un referéndum, o se acepta la posibilidad de celebrar infinitos referéndums; las posiciones intermedias otorgan derechos diferenciados a ciudadanos cuya única diferencia es haber "nacido" en momentos diferentes, algo escencialmente contrario al Art.01 de la Declaración Universal ${ }^{19}$.

La propuesta de celebración de un referéndum único, en el cual solo voten los ciudadanos catalanes actuales, no satisface la condición de Anonimidad tanto en relación al resto de ciudadanos españoles como a los ciudadanos catalanes del futuro.

Vamos a revisar la última de las cuestiones indicadas.

\section{4. ¿Cumple el "derecho a decidir" la condición de "no restricción del universo de elección"?}

La Condición de No Restricción del Universo de Elección alude al hecho de que la elección de la cuestión que se vota y las opciones que se pueden elegir, puede determinar si una votación colectiva es democrática o no ${ }^{20}$.

Si revisamos la propuesta de los partidos pro-independencia, estos plantean que los ciudadanos voten una pregunta del tipo “¿Quiere usted que Cataluña se constituya en República Independiente?" y que sus posibles respuestas sean "sí"y "no"

Y esto plantea una restricción importante en dos ámbitos: en las preguntas que se pueden hacer y en las respuestas que se pueden elegir, y ambas cuestiones hacen que este planteamiento se sitúe muy lejos del concepto de elección democrática. Vamos a verlo.

\subsection{Restringir las preguntas que se pueden hacer}

Los partidos pro-independencia argumentan una legitimidad histórica ${ }^{22}$ como base del derecho a hacer la consulta, pero supeditan la realización efectiva de la separación a las preferencias de los ciudadanos. Y una vez supeditada la definición territorial de España a las preferencias de los ciudadanos, no existe ninguna razón objetiva por la cual "el derecho a decidir" deba considerar a Cataluña, o a cualquier otra región, como una entidad indivisible, independientemente de la voluntad de estos ciudadanos.

Dicho de otra manera, si la mayoría de ciudadanos de Lérida, Gerona y Tarragona prefieren la independencia, pero la mayoría de ciudadanos de Barcelona prefiere seguir en España,...

$\square$ ¿Por qué debería imponerse a los ciudadanos de Barcelona la separación del resto de España [perdiendo así sus actuales derechos como ciudadanos españoles]?

$\square$ ¿Por qué no puede cada circunscripción dentro de Cataluña decidir de manera independiente si quiere seguir integrada o escindirse del resto del Estado español para constituir una nación independiente, que podrá ser una república, un reino,...?

19 Desde una línea de pensamiento complementaria, podríamos decir que subyace las actuales aproximaciones al concepto de Sostenibilidad, que no solo buscan optimizar el estado del mundo y su probabilidad de perdurar, sino también que las "generaciones futuras" disfruten de los mismos derechos que los habitantes actuales.

20 Aunque en sentido estricto las opciones elegibles siempre están restringidas, es fundamental que las opciones principales sean elegibles.

21 Este fue el formato de pregunta/respuesta elegido por las autoridades catalanas para la 'consulta' del 1 de octubre de 2017 , prohibida por el Tribunal Constitucional.

22 Esta legitimidad histórica es cuestionable, ya que España existe como identidad política desde al menos 1.000 años antes que Cataluña. Es significativo que Isidoro de Sevilla [ca. 630 CE, Bk IX,ii] solo describa en sus Etimologías la existencia de cuatro pueblos [gens] en España [Hispania]: gallegos, astures, cántabros y vascos. Isidoro no puede mencionar a los catalanes por el simple hecho de que todavía faltan varios siglos para su nacimiento como pueblo, que se producirá sobre el 'lienzo en blanco' que dejó la invasión musulmana del reino visigótico de España. 
૫ ¿Por qué debe obligarse a los ciudadanos catalanes a permanecer unidos, si diferentes regiones de Cataluña decidieran que prefieren diferentes caminos para el futuro?

Dado que ya se han manifestado diferencias entre las preferencias de los ciudadanos de diferentes partes de Cataluña... ¿por qué el referéndum no pregunta también a los ciudadanos "si algunas partes de Cataluña prefieren la independencia y otras no... prefiere usted mantener la integridad territorial con el resto de Cataluña o con el resto de España?".

No existe ningún motivo por el cual, si se abre la puerta a la "re-definición" territorial de España con base en las preferencias individuales, cualquiera de las opciones anteriores no sea válida. De hecho, no valorar dichas opciones cuestionaría el carácter "democrático" de la consulta, que mostraría, otra vez, un diseño pensado para favorecer la opción preferida por los partidos proindependencia, pero no necesariamente por la mayoría de ciudadanos españoles/catalanes.

Restringir las preguntas que se pueden hacer es una forma de limitar las respuestas que se pueden obtener; i.e., de evitar respuestas no deseadas incluso si alguna de ellas fuera la opción preferida por la mayoría de los ciudadanos. Es una forma nodemocrática de manipular elecciones favoreciendo unas opciones frente a otras; i.e., de lograr decisiones "aparentemente" democráticas que en realidad no lo sean.

\subsection{Restringir las respuestas que se pueden elegir}

Los partidos pro-independencia explicitan como posibles opciones elegibles "sí" y "no", pero lo cierto es que existen muchísimas diferencias posibles dentro del "sí" y dentro del "no".

Por ejemplo, un ciudadano puede preferir que Cataluña siga en España si se profundiza en el modelo de las autonomías o hacia un estado federal, pero que Cataluña se separe de España si se adopta una postura rígida que no acepte determinadas cuestiones que dicho ciudadano considere muy importantes. Para dicho ciudadano, ni el "sí" ni el "no" son su opción favorita.

Elegir entre "si" y "no" puede impedir a muchos ciudadanos expresar sus preferencias reales, y obligarlos a elegir de manera poco precisa.

Un planteamiento democrático de una consulta de esta naturaleza requiere que los ciudadanos puedan valorar todas las opciones posibles, y no limitarla a dos opciones que no describen [ni de lejos] la variedad de soluciones posibles. La consulta debería, al menos, valorar las propuestas de los principales grupos políticos, que podemos agrupar a grandes rasgos en:
Que todo siga igual.
Que se profundice en el modelo de Estado de las autonomías.
Que se avance hacia un Estado Federal.
Que se proclame una República Independiente.

Y aquí surge otro problema, porque no existe ninguna regla para elegir entre más de dos opciones que sea suficientemente aceptada por los expertos:

Si se elige la opción más votada [regla de la pluralidad], dicha opción no necesariamente será la más preferida, $\mathrm{e}$ incluso puede ser la menos preferida ${ }^{23}$.

Si utilizamos un método de votación preferencial, no existe ningún método aceptado por un número elevado de expertos para agregar los votos individuales [nos remite a la Imposibilidad de Arrow y resultado de Gibbard Satterthwaite].

Sin embargo, es nuestra opinión que cualquier regla que satisfaga el Criterio de Ganador de Condorcet, llevaría con elevada probabilidad a un resultado coincidente ${ }^{24}$.

\section{Recapitulación y conclusiones}

La revisión nos permite ver que el "derecho a decidir" en los términos propuestos por los partidos pro-independencia incumple tres premisas fundamentales de la Elección Social:

\section{La Anonimidad}

- Da más valor a los derechos voto- de los políticos/ciudadanos catalanes que a los del resto de políticos/ciudadanos españoles.

23 A esto se denomina 'Paradoja de Borda' y fue demostrado hace más de 200 años por J.C. de Borda. La probabilidad de que la regla de la pluralidad no elija la opción más preferida de entre las 4 opciones anteriores podría ser superior al $40 \%$ [Wright, 2009]

24 El motivo es que las opciones presentan una estructura 'Single Peaked' [Black, 1948], por lo que es poco probable que se produzcan relaciones cíclicas. Si se produjeran, nuestra regla preferida para resolverlas es Beatpath Schulze [Schulze, 2011]. 
Dan diferente valor a los derechos -voto- de los políticos/ciudadanos catalanes actuales que al de los políticos/ciudadanos catalanes futuros.

O

Dan más valor a las preferencias de los integrantes de los partidos independentistas que a las del resto de ciudadanos catalanes.

La Neutralidad: diseña la consulta para favorecer la elección de la opción de independencia frente a la de continuidad dentro del estado español.

- La No restricción del Dominio de Elección: promueve una única pregunta, y niega muchas otras posibles, independientemente de que podrían ser las preferidas por los ciudadanos.

- Acepta solo dos respuestas que podrían no ser las preferidas por los ciudadanos.

Por tanto, el planteamiento de estos partidos no puede ser considerado un derecho básico de la democracia, y su implementación en los términos demandados por dichos partidos llevaría a una decisión que, con elevada probabilidad, no sería democrática; i.e., que no representaría la voluntad de los ciudadanos, ni del conjunto de españoles, ni de los ciudadanos catalanes.

No obstante, puede cuestionarse que el procedimiento establecido en la Constitución Española atribuye mucho mayor valor a las preferencias de los políticos que a la de los ciudadanos, sobre todo en la preservación del statu quo. Es decir, si una propuesta de modificación de la delimitación de España no es aprobada por 2/3 de cada Cámara, no podrá ser valorada por los ciudadanos, independientemente de cuál sea su opinión, incluso si el 100\% de los ciudadanos estuviera a favor de dicha modificación.

Esto también incumple la condición de Anonimidad; 117 diputados u 89 senadores españoles poseen en la actualidad el derecho a imponer sus preferencias al resto de ciudadanos españoles, incluso si el $100 \%$ de estos ciudadanos sostuvieran la preferencia contraria. Si consideramos el número de españoles en el Censo Electoral [INE, 2016], equivale aproximadamente a otorgar al voto de un senador mayor valor que el voto de 200.000 ciudadanos españoles.

Esto hace cuestionable que un referéndum sobre la continuidad o no de Cataluña en España deba seguir el proceso actualmente establecido en la Constitución, al otorgar a los políticos españoles [y catalanes] un derecho de veto que podría llevar a una situación contraria a la preferencia real del conjunto de ciudadanos españoles en esta cuestión.

Por tanto, para enunciar las condiciones que permitirían una consulta democrática sobre la permanencia [o no] de Cataluña en España, no tomamos como referencia las condiciones establecidas en la Constitución, sino únicamente las cuestiones que se relacionan con las tres condiciones referidas: Anonimidad, Neutralidad y No restricción del Universo de Elección.

Desde estas condiciones, un procedimiento democrático para decidir la continuidad o no de Cataluña en España debería:

\section{Satisfacer la Anonimidad...}

Entre los ciudadanos actuales, otorgando el mismo valor al voto de todos los españoles, lo que implica:

- Admitir la consulta a los ciudadanos, eliminando la actual posibilidad de veto de las cámaras de representantes ${ }^{25}$.

- Recabar la opinión de todos los ciudadanos españoles, no solo los catalanes.

Entre los ciudadanos actuales $y$ futuros:

- Establecer condiciones que garanticen que la decisión actual no sea diferente de la que se tomaría dentro de unos meses, en cuanto se modificara ligeramente el censo electoral requiriendo:

- Un porcentaje de participación suficientemente elevado [e.g., $75 \%]^{26}$.

25 Los 'representantes' han argumentado mucho tiempo el efecto positivo de su 'veto' que -afirman- evita la 'inestabilidad inherente a las consultas ciudadanas'. Sin embargo, existen mecanismos que evitan la inestabilidad en las decisiones de largos electorados, como son utilización de mayorías cualificadas o dobles mayorías [o ambos, para cuestiones de especial importancia], utilización de reglas que satisfacen el Criterio de Ganador de Condorcet,... Frente a ello, el modelo actual de concentración de poder político en unos pocos representantes está mostrando una preocupante generalización de la corrupción [primacía del interés particular frente al interés general], y podría ser -conjuntamente con la utilización de reglas de votación inadecuadas- una de las causas de la inestabilidad política actual en España.

26 Para evitar que este mecanismo pudiera redundar en la capacidad de un $25 \%$ de ciudadanos de impedir la decisión, una condición equivalente es que si la participación es inferior al $75 \%$, se contabilice la diferencia entre la participación real y el $75 \%$ de los ciudadanos con derecho a voto, como si dichos ciudadanos hubieran votado a favor de preservar los derechos actuales/statu quo. 
- El voto favorable de una mayoría cualificada [e.g., 2/3 de ciudadanos].

○ Establecer un segundo criterio de mayoría que preserve los derechos de las minorías; la mayoría debe votar a favor de la opción de la independencia en ambos contextos: en Cataluña y en el resto de España ${ }^{27}$.

○ En caso de resultar positivo el resultado, el derecho de sus ciudadanos a convocar un referéndum similar [sea para volver a la situación actual o para independizar alguna parte dentro de la propia Cataluña] debe ser establecido como derecho fundamental en la Constitución Catalana en caso de decidirse la independencia.

Complementariamente, satisfacer la anonimidad entre ciudadanos actuales $y$ futuros implica satisfacer la Neutralidad intertemporal entre las opciones.

Satisfacer la condición de Dominio No

Restringido, evitando limitar las opciones que los ciudadanos pueden elegir de acuerdo con las preferencias de algunos individuos28:

$\square \quad$ Entre las preguntas a formular, debe añadirse una segunda en la consulta: ¿si en su circunscripción gana el "no", pero en la mayoría de circunscripciones catalanas gana el "sí", prefiere usted preservar la integridad territorial con el resto de Cataluña o con el resto de España?

Entre las respuestas que es posible elegir, es imprescindible incluir todas las opciones apoyadas por los principales partidos políticos, y al menos las cuatro indicadas arriba:

- Que se continúe el modelo actual.

- Profundizar en el Estado de las Autonomías.

- Desarrollar un modelo de Estado Federal.

- Que Cataluña se independice ${ }^{29}$. Lo contrario implicaría que la decisión podría ser impuesta, ya que la opción preferida por la mayoría de ciudadanos podría ser diferente a las opciones elegibles.

Estas podrían ser las condiciones que permitieran la celebración de una consulta "democrática" acerca de la cuestión de la continuidad o no de Cataluña en España. Cualquier otra condición para la celebración de dicha consulta incumpliría requisitos fundamentales para ser considerada democrática, según principios unánimemente aceptados en la Elección Social. Sería, en esencia, "anti-democrática", independientemente de si implica o no una votación.

Pero es importante destacar que si la consulta se celebra satisfaciendo las condiciones anteriores, tendría legitimidad democrática, independientemente de si este procedimiento no es aceptable desde el actual diseño de nuestra Constitución.

En sentido estricto, es posible diseñar una consulta democrática sobre la independencia [o no] de Cataluña, pero las condiciones que tendría dicha consulta y los riesgos que implicaría [especialmente para los ciudadanos catalanes] hacen dudoso que exista alguien interesado en convocarla.

\section{Epílogo}

Hemos visto las condiciones que permitirían tomar una decisión democrática sobre la continuidad o no de Cataluña en España. Sin embargo, este procedimiento hace que, en situación de igual número de ciudadanos apoyando el statu quo y la independencia, prevalezca el mantenimiento de la tendencia actual/statu quo frente a la independencia; i.e., asigna mayor valor a las preferencias de aquellos que prefieren continuar la tendencia actual.

Y se plantea la pregunta... ¿es esto democrático? La respuesta es que sí, lo que se justifica por tres objetivos que deben guiar las elecciones sociales:

El primero es preservar la Estabilidad de las sociedades, lo que requiere que reformar cuestiones estructurales de las sociedades sea más difícil que reformar cuestiones no estructurales [Barberá \& Jackson, 2004]. Un cambio estructural aprobado por una diferencia reducida

27 Alude a la necesidad de decidir en la actualidad, en condiciones similares a las que tendrían los ciudadanos catalanes futuros si ahora se aprobase la independencia y los futuros ciudadanos prefiriesen dicha vuelta atrás. Anticipamos que muchas veces puede ser imposible garantizar que esta posibilidad de vuelta atrás, pero al menos debe ser evaluada y realizar un diseño del procedimiento de votación que la facilite al máximo.

28 Aunque en cualquier elección es necesario 'limitar' las opciones elegibles, para que alguna de ellas alcance suficiente apoyo, esta limitación debe relacionarse con las preferencias de la mayoría de los ciudadanos, no con las de unos pocos políticos.

29 Esta opción sería conveniente desagregarla de entre los diferentes modelos propuestos por los partidos pro-independencia, ya que, aunque en la actualidad dichos partidos forman un bloque, en realidad defienden futuros muy diferentes para Cataluña. 
de votos puede fácilmente implicar que, si se repite la elección en un plazo reducido de tiempo, se obtenga el resultado opuesto, llevando así a una situación de elevada inestabilidad social. El segundo es la Eficiencia en el uso de los recursos de las sociedades. Los cambios estructurales requieren tiempo y uso elevado de recursos para ser implementados. De nuevo, si no existe una diferencia apreciable de votos a favor del cambio [i.e., si una gran mayoría de ciudadanos no mejora su estado], un cambio importante es un uso ineficiente de recursos.

Y el tercero es en términos de Racionalidad como maximización de la utilidad esperada. Los cambios importantes en períodos reducidos de tiempo implican elevada incertidumbre/ riesgo en comparación con el futuro más "cierto" de mantener tendencias de cambio/desarrollo más constantes. Si no hay una recompensa importante que se vaya a alcanzar [i.e., si una gran mayoría de ciudadanos no mejora su estado], un cambio incierto implica menor utilidad colectiva esperada que continuar la tendencia actual.

La mayoría de las personas prefieren que las decisiones públicas sean estables, eficientes y racionales, y esta preferencia global se superpone a las preferencias expresadas en consultas particulares, lo que favorece la compatibilidad de las mayorías cualificadas con la naturaleza democrática de la decisión en procesos que impliquen modificaciones estructurales.
Y de estas tres cuestiones, la última racionalidad de la decisión- es fundamental porque la forma que tiene un ciudadano/grupo de decidir si un cambio es racionalmente deseable o no, es comparar la utilidad que proporciona el contexto actual contra la que proveería el contexto que se crearía mediante el cambio ${ }^{30}$. Y cuando revisamos el modelo de Estado que propugna Constituïm encontramos varias cuestiones sorprendentes:

La primera es que todos los derechos ciudadanos de la propuesta Constituïm son compatibles con la permanencia de Cataluña en España. En concreto, la mayoría de nuevos derechos ciudadanos en la propuesta Cï aluden a su mayor influencia en ciertas decisiones colectivas [Cï, Título Séptimo], algo que es perfectamente posible sin necesidad de independencia ${ }^{31}$.

La segunda es que los ciudadanos catalanes ven restringidos sus actuales derechos al ámbito de Cataluña, e incluso dentro de Cataluña pierden algunos derechos importantes [e.g.; el derecho a utilizar el castellano en sus comunicaciones con la Administración ${ }^{32}$, el derecho a participar en la toma de decisiones colectivas en España y la UE,...].

La tercera es que en la propuesta de CÏ los partidos y políticos catalanes incrementan mucho su poder ${ }^{33}$, lo que cuestiona seriamente su imparcialidad en este proceso.

La cuarta es que Cï propone para la Asamblea un Régimen Electoral que haría que ésta fuera muy poco representativa; que implicaría, con elevada probabilidad, un bias ideológico persistente hacia el lado conservador, y que marginaría a las provincias menos pobladas $^{34}$. Si las elecciones a la Asamblea de

30 Las preferencias racionales entre cursos de acción no se establecen por las características de los cursos de acción elegibles, sino por las consecuencias [o estados del mundo] que se prevén alcanzar siguiendo cada curso de acción elegible [Savage, 1954]. La preferencia racional entre la permanencia o la independencia debe basarse en gran medida en la comparación del marco constitucional actual y el que se implantaría. A falta de constitución oficial, valoramos la propuesta Cï.

31 Aunque algunos derechos requeririan un cambio de la Constitución Española, esta modificación es posible sin necesidad de independencia Adicionalmente, la lectura de la propuesta CÏ deja algunas dudas importantes, ya que la definición de muchas de estas propuestas se deja a una hipotética Ley de Participación Ciudadana que sería ... ¿ ¿ redactada por políticos catalanes que en la actualidad no promueven dicha mayor participación ciudadana -salvo en el tema del referéndum independentista, y con las reservas ya indicadas-? ¿Por qué los derechos de participación ciudadana no se definen completamente en la propuesta Cï, para 'blindarlos' ante posibles cambios de opinión posterior de los políticos? La historia ha mostrado, ya demasiadas veces, que el derecho de los ciudadanos a controlar las acciones de los representantes es lo primero que los políticos eliminan en los procesos de redacción de constituciones.

32 El énfasis que pone Constituïm en incrementar las relaciones futuras con regiones con las que se tienen vínculos lingüísticos [Art. 7], y la urgencia en romper el vínculo lingüístico con España [Disposición Transitoria Primera], son relevantes por cuanto indican la voluntad de CÏ de romper cualquier vínculo con España lo antes posible, algo que resulta muy cuestionable por innecesario. Por otra parte, CÏ no valora que romper el vínculo lingüístico con España implica romperlo con toda Latinoamérica.

33 El Titulo Cuarto, Capítulos 1 y 2 detallan los poderes que los políticos catalanes tendrían en una hipotética Cataluña independiente, que son muy superiores a los actuales, empezando por el incremento de la duración de los mandatos un $20 \%$.

$34 \mathrm{Cï}$, Capitulo 2. Art 78 y 79 . El "régimen electoral" para la Asamblea detallado por Cï plantea distritos electorales reducidos [según los datos de población de Idescat, 2016, el 53\% de los distritos electorales elegiría un representante, y el $30 \%$ dos representantes], en un diseño más próximo a los sistemas mayoritarios de los países anglosajones que a los sistemas de representación proporcional utilizados en el resto de países. La falta de representatividad de los sistemas con reducido número de representantes por distrito fue puesta de manifiesto tan pronto como [Hare, 1860 o Dodgson, 1888]. Cİ propone un sistema de listas abiertas, que tiende a promover la primacía de la persona y con ello el elitismo [los cargos políticos se restringen en mayor medida a ciudadanos con mayor riqueza]. Además, Cï propone que "Los diputados [...] políticamente, sólo responderán ante los ciudadanos de la circunscripción electoral por la que han sido elegidos", algo que a nuestro juicio es un grave error conceptual; el gobierno de un 'todo' siempre necesita decisiones que trascienden los intereses de las "partes". Para una revisión de la persistencia de un bias ideológico hacia el lado conservador en sistemas mayoritarios, ver Colman \& Pountney, 1978. Complementariamente, el distrito electoral único para la elección del Presidente, implica otorgar la decisión a los habitantes de la provincia de Barcelona [con un $75 \%$ de electores]. La influencia sobre el futuro político de Cataluña de las provincias o regiones menos pobladas [Lleida, Girona y Tarragona, o el Arán] es prácticamente cero. Esto podría evitarse mediante el diseño de un sistema bicameral; elección indirecta del presidente,... 
una hipotética Cataluña independiente se realizaran siguiendo el sistema propuesto por Cİ:

Las decisiones que tomaría dicha Asamblea serían muy diferentes a las que tomaría el conjunto de catalanes, y con ello la evolución en el largo plazo de la sociedad catalana sería muy diferente a la que dicha sociedad preferiría.

El futuro de Cataluña sería decidido casi autónomamente por unos pocos barceloneses. Lleida, Girona, Tarragona y el Arán serían políticamente irrelevantes.

En resumen, salvo algún incremento de participación en la toma de decisiones públicas [inexplicablemente poco "definido" en el texto], la propuesta de Constituïm no aportaría derechos nuevos a los ciudadanos catalanes pero, en cambio, recortaría muchísimo sus derechos actuales [pierden sus derechos en el resto de España y la UE] y sentencia un gran incremento de concentración del poder en los políticos ${ }^{35}$ dentro de un régimen electoral con importantes errores de diseño, y que margina a las provincias menos pobladas.

Organizar un proceso independentista en el cual los ciudadanos tienen la certeza de perder mucho, deja bastantes dudas en relación con lo que pueden ganar, y lo que podrían ganar pueden lograrlo sin necesidad de un proceso de independencia -que implica un riesgo elevado-, no resulta racional. Además, el hecho de que los únicos agentes que obtendrían derechos que no podrían adquirir sin la independencia son los propios políticos y partidos pro-independencia, cuestiona otra vez la legitimidad de sus acciones.
Sin embargo, el debate actual sobre la legitimidad de las decisiones colectivas votadas o del "poner urnas en la calle"- se presenta como oportunidad para desplazar el punto de mira desde el análisis del "derecho a decidir únicamente sobre la independencia o no de ciertos territorios" en todas las cuestiones importantes para los ciudadanos, y especialmente en la conformación del marco regulatorio [Constitución y Leyes].

Para ello, no hace falta reinventar la rueda. Tenemos un modelo que lleva ya funcionando mucho tiempo en un país suficientemente cercano y parecido al nuestro; Suiza, cuya Constitución define un modelo federal con elevado control ciudadano en relación con el marco constitutivo/legislativo, en un diseño que incorpora un gran equilibrio territorial y que ha demostrado elevada estabilidad a lo largo de su historia ${ }^{37}$.

El gran interés del debate actual sobre la legitimidad democrática [o no] del derecho a decidir es que nos permite abrir el debate sobre la necesidad de democratizar nuestro sistema político, incorporando el derecho real de los ciudadanos a decidir en las cuestiones más importantes, y reduciendo el impacto negativo de la actual concentración excesiva de poder en unos pocos "representantes" [e.g., la corrupción, desigualdad económica,... ], que con frecuencia no parecen actuar por el interés general, sino por intereses particulares.

Como hemos dicho antes, un referéndum democrático para la independencia [o no] de Cataluña es posible, pero las condiciones en que debería celebrarse hacen que su celebración difícilmente entusiasme a nadie. Lo realmente interesante es aprovechar la situación actual para mejorar, mediante una

35 Esta elevada concentración de poder suele tener consecuencias negativas, e.g, se considera una de las principales causas de la elevada y creciente desigualdad económica en las sociedades occidentales [ver Alvira, 2017. Anexo II].

36 Resulta significativo que el 'derecho a decidir' en los términos descritos, es otra vez una decisión planteada por los políticos, no por los ciudadanos, y que se relaciona con las necesidades de esos políticos, y no de los ciudadanos. Los políticos españoles [incluyendo a los catalanes] siguen resistiéndose a que sean los ciudadanos quienes elijan sobre qué quieren decidir.

37 La evolución de Suiza desde una confederación de tres cantones con finalidad de defensa mutua [finales del SXIII], hasta un estado federal que integra 26 cantones con un gobierno central representativo compatible con el equilibrio territorial y el control popular, presenta un interés notable en el momento actual de crisis de los gobiernos representativos [o en otros términos, de crisis de la inadecuada definición de democracia por Schumpeter, 1943]. En la Constitución Suiza [CS] se detallan perfectamente todas las herramientas de participación ciudadana y control político [Titulo 4, Capitulo 2 , Art 138-142], incluyendo los umbrales necesarios en cada procedimiento [algo inexplicablemente ausente en el documento Cï], en un modelo de estado federal que podría adaptarse con facilidad al caso español, donde los cantones suizos equivaldrían a las comunidades autónomas españolas. El modelo suizo es interesante también en el momento actual en que algunas regiones españolas reclaman un marco diferenciado de derechos alegando singularidades históricas. En primer lugar es necesario indicar que la revisión de la historia muestra que todas las regiones españolas son históricas. Tan histórico es el País Vasco como Galicia, Asturias, Cantabria o Andalucía [Bética en la Hispania Romana, y anteriormente localización del Reino de Tartessos]. Tanto lo es Cataluña como Castilla la Mancha o la Región de Murcia. Y en segundo lugar, es significativo que la CS no consigna diferencias históricas entre los cantones -pese a que dichas diferencias existen-; todos los cantones suizos poseen los mismos derechos.

En una Democracia la igualdad del poder político no solo se refiere a sus ciudadanos; también a las regiones. Por ello, en su prólogo la CS afirma el protagonismo tanto del pueblo suizo como de sus regiones [The Swiss People and the Cantons]. Es significativo que Suiza haya sido recurrentemente considerado el mejor ejemplo de país democrático a lo largo de la historia [Maquiavelo, 1513; Rousseau, 1754; Hattersley, 1930; el propio Schumpeter, 1943,...]. 
reforma constitucional ${ }^{38}$, el marco de derechos de los ciudadanos españoles reduciendo la actual elevada concentración del poder en España en unos pocos políticos, que está causando graves disfunciones del conjunto.

\section{Agradecimientos}

Este artículo se ha beneficiado de comentarios técnicos recibidos del Prof. Nicolaus Tideman y otro experto en elección social que ha preferido permanecer anónimo. También de la interpretación del texto en Latín de las Etimologías por Mart Smeijsters. En cualquier caso, la responsabilidad por las ideas expresadas corresponde solo al autor.

\section{Bibliografía}

Alvira, Ricardo (2017) “Segregación Espacial por Renta. Concepto, medida y evaluación de 11 ciudades españolas", Cuadernos de Investigación Urbanística, 114, Sepoct 2017. http://polired. upm.es/ index.php/ciur/article/view/3563

Aristóteles (344 AEC) La Política, traducción de Pedro Simón Abril, ediciones Nuestra Raza

Arrow, Kenneth J. (1951/1963) Social Choice and individual values, Cowles Foundation for research in economics at Yale University, $2^{\text {nd }}$ edition (1963), Ed. John Wiley \& Sons, http:// cowles.yale.edu/sites/default/files/files/ $\mathrm{pub} / \mathrm{mon} / \mathrm{m} 12$-2-all.pdf

Asamblea General De Las Naciones Unidas, AGNU (1948) Declaración Universal de los Derechos Humanos, http:// www.un.org/es/documents/udhr/UDHR booklet_SP_web.pdf

Barberá, Salvador \& Jackson, Matthew O. (2004) "Choosing How to Choose: SelfStable Majority Rules and Constitu tions", http://pareto.uab.es/ sbarbera/SB-MJ\%20CHOOSE\% 20Quarterly.pdf

Colman, Andrew \& Pountney, Ian (1978) "Borda"s Voting Paradox: Theoretical Likelihood and Electoral Occurrences", DOI: $10.1002 / \mathrm{bs} .3830230103$

Duncan Black (1948) "On the rationale of group d e c i s i o n - m a ki n g”, http://www.jstor.org/stable/1825026
Borda, Jean Charles De (1781) "Mémoire sur les élections au scrutin", Mémoires de L'Académie Royale des Sciences, pp. 657-664

Comisión Europea Para La Democracia A Través Del Derecho, CEDD (2009) "Código de buenas prácticas sobre referendos", Estudio No. 371/2006, http://www. venice.coe.int/webforms/documents/de fault.as px? pdffile = CDL-AD (2007)008rev-spa

Cortes Generales De España (1978) Constitución Española, https:// www.boe.es/diario_boe/txt.php?id=B OE-A-1978-31229

Constituïm (2016) "El debate de las ideas: Una propuesta de Constitución como herramienta de reflexión", http:// constituim.cat/images/docs/ESP.pdf

Dodgson, Charles (1884) The principles of parliamentary representation, https://archive.org/details/ThePrinciple sOfParliamentaryRepresentation

Hare, Thomas (1860) "On the Application of a New Statistical Method to the Ascertainment of the Votes of Majorities in a More Exhaustive Manner", reprinted from Journal of the Statistical Society of London, Vol. 23, No. 3. (Sep., 1860), pp. 337-356, http://www.votingmatters.org.uk/ISSU E25/I25P1.pdf

Hattersley, Alan F. (1930) A Short History of Democracy, Cambridge University Press

Instituto Nacional De Estadística, INE (2016) Elecciones a Cortes Generales del 26 de junio de 2016, Nota de Prensa, 9 de mayo de 2016, http://www.ine.es/ prensa/np967.pdf

Isidore Of Seville (600-630 CE) Etymologies, translation and notes by Stephen A. Barney, W. J. Lewis, J. A. Beach and Oliver Berghof in 2006. Cambridge: Cambridge University Press

Machiavelli, Nicolo (ca. 1513) Discourses on Livy, Book I; translated by Harvey C. Mansfield and Nathan Tarcov in 1996, The University of Chicago, http://www.constitution.org/mac/discli vy1.htm\# 1:01

May, Kenneth (1952) "A Set of Independent Necessary and Sufficient Conditions for

38 Nos alineamos con Aristóteles [344 ACE]; la fuerza de las normas se debe en gran parte a su perduración en el tiempo. No se trata de modificar continuamente los títulos fundamentales de la Constitución Española, ya que entonces sus preceptos perderían valor. Pero es innegable que España y los españoles han cambiado muchísimo desde 1978, y en muchos aspectos lo que en 1978 era óptimo, ya no lo es. Además, la Constitución admite perfectamente pequeñas reformas parciales más frecuentes, que preserven la mayoría de preceptos que funcionen adecuadamente. Es significativo que cuando Solón hizo pública su propuesta de Constitución para Atenas [ca. 594 AEC], lo hizo en tablas de madera [axones] en vez de en piedra, para que no 
Simple Majority Decision". http://www.eecs.harvard.edu/cs286r/c ourses/fall 1 1/papers/May52.pdf

Ober, Josiah (2008) "The original meaning of "democracy": Capacity to do things, not majority rule", Version 1.0, DOI: 10.1111/j.1467-8675.2008.00471.x

Savage, Leonard J. (1954) The Foundations of Statistics, New York, Wiley.

Schulze, Markus (2016) "A new monotonic, clone-independent, reversal symmetric, and Condorcet-consistent single-winner election method", h t t p : // m - s c hulze.9 mail.d e/ schulze1.pdf

Schumpeter, Joseph A. (1943) Capitalism, Socialism and Democracy, Routledge

The Swiss Confederation, TSC (1999) Federal Constitution of the Swiss Confederation, https:/www.admin.ch/ opc/en/classified - compilation/ 19995395/201702120000/101.pdf 